\section{A Manual of Psychological Experiments}

By Edwin Garriques Boring, Herbert Sidney Langfeld, Harry Porter Weld, and collaborators. Pp. ix $+198+3$ plates. (New York: John Wiley and Sons, Inc.; London: Chapman and Hall, Ltd., 1937.) 8s. 6d. net.

$\mathrm{T}$

HIS is an elementary manual of psychological experiments suitable for first-year students and containing about sixty experiments, mostly new. Besides the editors, seventeen other psychologists have collaborated to produce the book. The work is designed apparently to accompany the widely used general text-book in psychology by the same authors, but it can also be used together with any good textbook.

Many of the fifty-nine experiments are planned on traditional lines; twenty-three are concerned with psychophysics and sensation, seven are on perception, eight on learning and the rest on emotion, action, thought and personality. The methodology of each experiment is given briefly and clearly together with a number of questions and a few essential references.

An advantage of the course of experiments is the simple and inexpensive apparatus that is required. A disadvantage is the absence of the more recent experiments used in researches in Gestalt psychology. There is only one experiment on memory and none on attention, will, imagination, perseveration, oscillation, or fatigue. It is a relief to see that the plethysmograph is not introduced as a measure of affectivity. Most of the experiments are planned to take about one hour ; a few take about two hours and can be performed with large or small groups.

A short chapter is included on the computation of a few statistics, but no instruction is given in the psychophysical methods.

The manual is to be recommended for use by students in England, and could also be used to much advantage in tutorial and extension classes in psychology.

J. I. CoHeN.

\section{A Textbook of General Botany :}

for Colleges and Universities. By Richard M. Holman and Prof. Wilfred W. Robbins. Fourth edition. Pp. xvii +664. (New York : John Wiley and Sons, Inc.; London: Chapman and Hall, Ltd., 1938.) 20s. net. 7 HE subject-matter in the fourth edition of this 1 familiar text-book has not been materially changed, though in the light of most recent research it has been brought up to date. It is a pity that the subject-matter has not been modified, for it is based essentially on the morphological concept. Physiology receives scant treatment; the chapter on evolution and heredity is wellnigh out of date and genetics is practically ignored. Research on the more practical side of botany, and especially strictly economic botany, is going on apace, especially in the country of origin of this book, yet it scarcely receives a menticn.

These blemishes are unfortunate, for works by the late Prof. Holman and Prof. Robbins are well known and widely used. The book, as it is, brings that narrow conception of botanical science to the reader which was peculiar to the academic student of twenty years ago. Substantial changes are slowly taking place, and it is to be regretted that such an otherwise authoritative and well-written text gives so little attention to them.

\section{The Farming Year}

By Prof. J. A. Scott Watson. Pp. $144+64$ plates. (London, New York and Toronto : Longmans, Green and Co., Ltd., 1938.) 7s. $6 d$. net

$T$ HIS excellent little book has been written at the request of the National Federation of Young Farmers' Clubs. The farmer's son may be familiar with the type of farming practised in his district, but in most cases he will not have had the opportunity of taking at first hand a general view of our very varied husbandry. The next best thing is to have the situation briefly and accurately set out by a competent observer. Prof. Scott Watson has written his account in very simple style, and continually directs the attention of his readers to the causes that have operated to mould agriculture into its present form. The main styles of farming each form the subject of a chapter, and the scope is wide enough to include vegetables and flowers, farming under glass, and fruit. An outstanding feature of the book is the quality of the numerous illustrations, which with their well-phrased captions are full of information.

Readers other than young farmers will be found for this book. For the townsman, young or otherwise, it will provide a very readable account of an industry that makes as big a demand as any on the technical skill and business ability of its members.

\section{A Swahili Dictionary of Plant Names}

By P. J. Greenway. Pp. xvi+112. (Dar es Salarm : Government Printer, 1937.) $3 s$.

RR. GREENWAY has performed a very valuable 1 service to all interested in the life of the East African native by the preparation of this dictionary. Hitherto the available information was scattered through larger dictionaries or recorded only in botanical papers or on herbarium sheets. Now the accurate identification of the native names of medicinal, food and other plants will be greatly simplified.

Under each native name the English equivalent, if any, is given, followed by a brief description and the scientific name and family. Notes on the uses of the various species are also given, and there is a list of native morphological terms and a botanical glossary.

As Mr. Greenway remarks in his introduction, the vegetable kingdom plays a very important part in the economy of the African native. A thorough knowledge of native usage in plant nomenclature is therefore a valuable asset in understanding the African mentality, and the publication of this well-prepared and handy dictionary will be welcomed by all those concerned with study and administration in East Africa. 